\title{
Newer Stents for Unresectable Malignant Distal Biliary Obstruction: Striving for Perfection!
}

\author{
jimil Shah ${ }^{1}$ Surinder Singh Rana ${ }^{1}$ \\ 1Department of Gastroenterology, Post Graduate Institute of \\ Medical Education and Research, Chandigarh, India
}

\begin{abstract}
Address for correspondence Surinder Singh Rana, MD, DM, AGAF, FASGE, FSGEI, Department of Gastroenterology, Post Graduate Institute of Medical Education and Research, Chandigarh 160 012, India (e-mail: drsurinderrana@gmail.com).
\end{abstract}

\begin{abstract}
Keywords

- stent

- pancreatic cancer

- jaundice

- endoscope

Endoscopic biliary stenting is one of the most commonly used palliative procedure in patients with unresectable malignant distal biliary obstruction. Biliary stenting can be performed with either plastic or metallic stents. Stent occlusion and migration are important limitations of currently available stents. Variety of newer stents with varying designs and stent materials like stents with antimigratory properties, antireflux stents, drug-eluting stents, radioactive stents, and bioabsorbable stents are being developed to overcome the limitations of currently available stents. In this article, we are discussing two articles on the newer stent designs (plastic and metal stents) for biliary drainage in patients with unresectable malignant distal biliary obstruction.
\end{abstract}

Endoscopic biliary stenting is one of the most commonly used palliative procedure in patients with unresectable malignant distal biliary obstruction. The palliative stenting is usually performed either for cholangitis or before palliative chemotherapy or for symptomatic relief of pruritus. Biliary stenting can be performed with either plastic or metallic stents. Although metallic stenting is costlier than plastic stents, duration of hospitalization and need for repeated procedures due to stent blockage is less with metallic stents compared with plastic stent making it a cost-effective option even in countries with low endoscopic retrograde cholangiopancreatography (ERCP)-related costs..$^{1-3}$ However, plastic stent still remains one of the most commonly used modalities for palliative biliary drainage in patients due to cost constrains in developing countries like India. In recent years, various plastic stent designs have been built to decrease the chances of stent blockage and increase the stent patency. One of the most extensively explored options is to increase the diameter of the plastic stent. Despite initial enthusiasm of increasing stent diameter to reduce the risk of stent blockage, recent studies have shown no additional advantage for stents of more than $10 \mathrm{~F}$ in reducing the risk of plastic stent blockage. ${ }^{4-6}$ Similarly, newer stent designs like distal windsock design, a winged stent without central lumen or specialized coating, have been also built but without consistent results showing benefit in increasing stent patency rates. ${ }^{7}$ Recently, a double-layer stent design has been developed which has shown better stent patency rates compared with conventional plastic stents. ${ }^{8.9}$ In that stent, the inner layer is made up of fluorine coating, which has a water-repellant property, to minimize the bile adhesion and the outer rigid material provides stiffness necessary to guide smooth insertion. ${ }^{10}$ Similar to plastic stents, designs of metallic stents have also evolved in recent years to increase its patency and reduce the risk of migration. Initially, uncovered metallic self-expanding metallic stents (SEMS) were used in patients with unresectable malignant distal biliary obstruction; however, covered SEMS has shown to have a better stent patency compared with uncovered SEMS without much increase in the complications rate. ${ }^{11}$ One of the major limitations associated with covered SEMS is the risk of migration and shortening after deployment. Recently, laser-cut covered SEMS are considered to published online

November 18, 2020
DOI https://doi.org/

$10.1055 / \mathrm{s}-0041-1728841$ ISSN 0976-5042
(O2020. Society of Gastrointestinal Endoscopy of India.

This is an open access article published by Thieme under the terms of the Creative Commons Attribution-NonDerivative-NonCommercial-License, permitting copying and reproduction so long as the original work is given appropriate credit. Contents may not be used for commercial purposes, or adapted, remixed, transformed or built upon. (https://creativecommons.org/licenses/by-nc-nd/4.0/). Thieme Medical and Scientific Publishers Pvt. Ltd. A-12, 2nd Floor, Sector 2, Noida-201301 UP, India 
have better deployment property, without shortening of the stent. ${ }^{12,13}$ However, there is no head-to-head trial of braided versus laser-cut SEMS in terms of efficacy, risk of blockage, or risk of migration.

In this news and views, we are discussing two articles on the newer stent designs for biliary drainage in patients with unresectable malignant distal biliary obstruction. First study has explored a newly designed $12 \mathrm{~F}$ plastic stent and compared it with historic controls who had had 10F plastic stents or SEMS insertion for biliary obstruction and the second study has explored the efficacy and safety of new lasercut fully covered SEMS. Although neither of the studies are large multicentric randomized trials, they throw some light on future stent development for biliary drainage in patients with unresectable malignant distal biliary obstruction.

Deprez et al conducted a single-center prospective study in Belgium between March 2015 and June 2017 on the efficacy and safety profile of the newly designed 12F plastic stent (PBD-Y0011) in patients with histologically proven unresectable distal malignant biliary obstruction. ${ }^{14}$ This novel stent has three layers, a proximal X-ray mark, three flaps at each end, and protective sleeves to keep the proximal and distal flaps straight. Inner layer of stent is coated with fluorine, metal coil constitutes the intermediate layer, and outer layer is made of a special resin. Deprez and colleagues have also described the method of stent insertion using push-and-pull endoscope movements and up-down movement of the outer control knob rather than using elevator. Stent length varied between 5,7 , and $9 \mathrm{~cm}$ and endoscopist decided stent length based on the length of stricture. All ERCP procedures were done using therapeutic duodenoscope with $4.2 \mathrm{~mm}$ working channel (TJF-Q180V; Olympus Europe, Berchem, Belgium). Recurrent biliary obstruction (RBO) was defined in the presence of stent dysfunction (with or without cholangitis) or symptomatic migration. Stent dysfunction was defined as dilated bile duct with biliary pain, presence of cholestasis (greater than twofold normal values), or jaundice (total bilirubin $>3 \mathrm{mg} / \mathrm{dL}$ ) with or without fever at least 48 hour after the procedure. In presence of stent dysfunction, the authors have also evaluated site, cause, and severity of stent occlusion by detailed examination the removed stent. After that, stent patency was checked using water irrigation test using three water pressures $(110,350$, and $550 \mathrm{mmH}_{2} \mathrm{O}$ ) for 3-minute durations and then the stent was scored as "open," "partially occluded," or "completely occluded" for each water pressure. Moreover, all retrieved stents were dissected at $1 \mathrm{~cm}$ cross-section and visually evaluated to identify the location and degree of occlusion. Nonsignificant occlusion was defined as an unimpeded view through $>50 \%$ of the lumen through all stent segments. Significant or complete occlusions were recorded when $\geq 50 \%$ or all, respectively, of the lumen was seen to be obstructed in at least one segment. These prospectively enrolled patients undergoing $12 \mathrm{~F}$ plastic stent placement were compared with historic controls who underwent $10 \mathrm{~F}$ plastic stenting, fully covered self-expandable metallic stenting (FCSEMS), or uncovered metallic stenting (UCSEMS) for unresectable distal bile duct malignancy. The patients were randomly selected by frequency matching for age, sex, metastatic disease, and etiology of obstruction.
In this study, the authors have included a total of 72 patients; 24 patients underwent $12 \mathrm{~F}$ plastic stent placement prospectively and they were compared with historic cohort of patients who underwent $10 \mathrm{~F}$ plastic stenting or FCSEMS or UCSEMS (16 patients in each group). Median age, gender distribution, etiology of distal bile duct obstruction, pre-ERCP bilirubin levels, and bile duct diameter and stricture length were comparable between groups. Around $70 \%$ of patients had carcinoma of pancreas, $75 \%$ patients had metastatic disease, and the median length of bile duct stricture was $20 \mathrm{~mm}$. The technical success rate was $100 \%$ in all the four groups. Median stent patency duration was 106, 51, 154, and 136 days in $12 \mathrm{~F}$ plastic stent, $10 \mathrm{~F}$ plastic stent, FCSEMS, and UCSEMS groups, respectively. The 10F plastic stent had significantly lower stent patency rate compared with FCSEMS or UCSEMS ( $p<0.01)$; however, the differences were not statistically significant between other groups. Over a median follow-up of 127 days (32-356 days), RBO rate for the $12 \mathrm{~F}$ plastic stent was significantly lower compared with the $10 \mathrm{~F}$ plastic stent ( $50 \%$ vs. $81.3 \% ; p=0.046$ ) and it was comparable with the FCSEMS (43.8\%; $p=0.436$ ) or UCSEMS (68.8\%; $p=0.234)$. None of the patients in the $12 \mathrm{~F}$ group had RBO due to stent migration while 4 patients in the $10 \mathrm{~F}$ group and 1 patient in the FCSEMS group had RBO due to stent migration. Eleven $12 \mathrm{~F}$ plastic stents were examined after removal for suspected stent dysfunction; however, only 4 patients had occlusion in the irrigation test while 7 stents had only partial clogging on visual inspection. The cause of cholestasis in those 7 patients was not evaluated in detail in this study. A 30-day mortality was noted in 3 patients in the $12 \mathrm{~F}$ group, 1 patient in the 10F group, and none in the SEMS group. Although the difference was not statistically significant, the authors have not explored the cause of higher 30-day mortality in the $12 \mathrm{~F}$ group which requires careful evaluation in future studies. Post ERCP adverse event rates were also comparable between all groups. The authors concluded that this newly designed $12 \mathrm{~F}$ plastic stent looks promising in patients with unresectable distal malignant biliary obstruction with similar stent patency and rates of RBO as FC/UC-SEMS.

Marui and colleagues, in a retrospective, observational, single-center study, explored a newer laser-cut FCSEMS (LC-CSEMS) for unresectable malignant distal biliary obstruction. ${ }^{15}$ The new LC-CSEMS (X-Suit NIR covered biliary metal stent; Olympus Medical Systems, Tokyo, Japan) is 10 $\mathrm{mm}$ in diameter and 8 or $10 \mathrm{~cm}$ in length. ${ }^{15,16}$ The stent has unique zigzag design composed of thick and thin struts made of nitinol. Thick struts maintain the stent form and provide a good radial force, and contribute to maintaining both SEMS position and the bile duct lumen. In contrast, the thin struts can be deformed in each mesh unit along the bile duct to ensure conformability of the stent, which enables the SEMS to fit into various bile ducts. Also, the stent has flared ends to prevent migration, larger radiopaque markers to increase the visibility on fluoroscopy, and a simple delivery system for easy stent placement. RBO was defined as a composite end point of either stent occlusion or symptomatic migration. In this study, all the stents were deployed through the papilla in duodenum. A total of 76 patients underwent LC-CSEMS 
placement during the study period for unresectable malignant distal biliary obstruction and 24 patients were excluded from the analysis due to various causes with 52 patients being finally included in the study. Majority of the included patients had carcinoma pancreas and had undergone prior endoscopic drainage with either nasobiliary tube or plastic stents. Seventy-five percent patients had placement of 8 -cm LC-CSEMS and 75\% of patients had undergone palliative chemotherapy or chemoradiotherapy after stent placement. Technical success was achieved in all patients and authors have not described any incidence of technical failure or maldeployment during the initial stent placement. Over a median follow-up of 159 days (83-248 days), 8 patients had RBO, with stent occlusion in 6 patients and distal stent migration in 2 patients. The stent was occluded due to sludge in 2 patients and with food impaction, tumor overgrowth, mucosal hyperplasia, or poor expansion in one patient each. The median time to RBO with LC-CSEMS was 445 days. Although the authors did not encounter any serious adverse events due to SEMS, 5 (10\%) patients had mild pancreatitis, $4(8 \%)$ patients had asymptomatic migration, 3 (6\%) patients had nonocclusive cholangitis, and $2(4 \%)$ patients had cholecystitis. Stent removal was attempted in 10 patients due to RBO $(n=3)$, pancreatitis $(n=1)$, nonocclusive cholangitis $(n=2)$, asymptomatic migration $(n=2)$, and abdominal pain ( $n=1)$ after a median time of 89 days (1-252 days) of placement. Stent removal was possible in 9 patients with either snare or rat tooth forceps. In one patient, stent removal was not possible due to breakage of stent while attempted removal which was successfully rescued with an additional LC-CSEMS inside the initial stent. Overall, the authors have noted encouraging results of this new LC-CSEMS for unresectable malignant distal biliary obstruction in terms of stent patency and reintervention including stent removal. However, further prospective studies comparing effects with standard braided CSEMS are required to compare clinical efficacy and RBO before its routine clinical use.

\section{Commentary}

Palliative drainage of the obstructed biliary system is required in many patients of unresectable malignant distal biliary obstruction like carcinoma head of pancreas, distal cholangiocarcinoma, or ampullary carcinoma. With advancement in palliative chemoradiotherapy, life expectancy has increased even in patients with unresectable malignant distal biliary obstruction which requires stent with higher stent patency and lower risk of recurrent stent occlusion. Initially plastic stents were used for biliary drainage in such patients; however, they are associated with recurrent biliary obstruction and repeated ERCP sessions with prolonged hospitalization which increases morbidity and total cost of the treatment. With the advances in the treatment protocol, initially uncovered and now covered metallic SEMS are the preferred option for biliary drainage in such patients. ${ }^{11}$ However, plastic stents are still widely used in countries with limited resources like India. We need better plastic stent designs, which is associated with stent patency time better than conventional plastic stents and equal to SEMS. Recently, Matsubara et al conducted a single-center retrospective study on use of $10 \mathrm{~F}$ double-layer plastic stent for preoperative drainage in patients with resectable malignant distal biliary obstruction. In their study also, the new double-layer plastic stent had higher stent patency rate compared with $7 \mathrm{~F}$ or $8.5 \mathrm{~F}$ conventional plastic stents. ${ }^{9}$ These studies show that changing stent design and diameter might give the answer for optimal plastic stent placement in patients with distal biliary obstruction. Similar to plastic stents, the risk of acute cholecystitis and migration is the major shortcoming in current FCSEMS designs. As braided SEMS are associated with the risk of shortening, endoscopists usually prefer long size of SEMS which is associated with increased risk of cystic duct blockage. ${ }^{16}$ With LC-CSEMS, the risk of stent shortening is lower and endoscopist can choose a smaller size of SEMS according the stricture length. Moreover, such LC-CSEMS can be very useful in hilar stricture which requires precise deployment. However, in a recent study by Marui et al, the authors have not used small-sized SEMS and they have not explored their benefits in hilar strictures, which require further exploration..$^{15}$ In this study, all except one LC-CSEMS were removed with snare or rat tooth forceps which points their potential use even in patients with benign biliary strictures.

To conclude, armamentarium of ERCP stents in patients with unresectable malignant distal biliary obstruction is increasing with newer stent designs in both plastic and metallic stents. With these designs, we hope to have more cost-effective options of stents for patients in near future. Development of newer stents is an evolving field with a variety of designs and stent materials like stents with antimigratory properties, antireflux stents, drug-eluting stents, radioactive stents, and bioabsorbable stents being developed in search of an ideal stent. An ideal stent would be a customized functional stent designed to cater to the disease as well as the anatomic characteristics of a particular patient. The era of personalized medicine is here!

\section{Funding \\ None.}

\section{Financial Disclosures \\ None.}

\section{Conflicts of Interest}

None declared.

\section{Reference}

1 Walter D, van Boeckel PGA, Groenen MJ, et al. Cost efficacy of metal stents for palliation of extrahepatic bile duct obstruction in a randomized controlled trial. Gastroenterology 2015; 149(1):130-138

2 Yoon WJ, Ryu JK, Yang KY, et al. A comparison of metal and plastic stents for the relief of jaundice in unresectable malignant biliary obstruction in Korea: an emphasis on cost-effectiveness in a country with a low ERCP cost. Gastrointest Endosc 2009;70(2):284-289

3 Sawas T, Al Halabi S, Parsi MA, Vargo JJ. Self-expandable metal stents versus plastic stents for malignant biliary obstruction: a meta-analysis. Gastrointest Endosc 2015;82(2):256-267.e7 
4 Siegel JH, Pullano W, Kodsi B, Cooperman A, Ramsey W. Optimal palliation of malignant bile duct obstruction: experience with endoscopic 12 French prostheses. Endoscopy 1988; 20(4):137-141

5 Wagh MS, de Bellis M, Fogel EL, et al. Multicenter randomized trial of 10-French versus 11.5-French plastic stents for malignant biliary obstruction. Diagn Ther Endosc 2013;2013:89191 $510.1155 / 2013 / 891915$

6 Kadakia SC, Starnes E. Comparison of 10 French gauge stent with 11.5 French gauge stent in patients with biliary tract diseases. Gastrointest Endosc 1992;38(4):454-459

7 Pfau PR, Pleskow DK, Banerjee S, et al. ASGE Technology Assessment Committee. Pancreatic and biliary stents. Gastrointest Endosc 2013;77(3):319-327

8 Ito K, Igarashi Y, Mimura T, Kishimoto Y, Kikuchi Y, Okano N. Efficacy of the new double-layer stent for unresectable distal malignant biliary obstruction: a single-center retrospective study. Diagn Ther Endosc 2012;2012:680963

9 Matsubara T, Nishida T, Hayashi S, et al. Comparison of double-layer large-diameter and conventional small-diameter plastic stents for preoperative biliary drainage in resectable distal malignant biliary obstruction. Sci Rep 2020;10(1):13222

10 Double layer biliary stent. Olympus America Web sitehttps:// medical.olympusamerica.com/products/double-layer-biliary-stent. Accessed Nov 15, 2020
11 Isayama $\mathrm{H}$, Komatsu $\mathrm{Y}$, Tsujino $\mathrm{T}$, et al. A prospective randomised study of "covered" versus "uncovered" diamond stents for the management of distal malignant biliary obstruction. Gut 2004;53(5):729-734

12 Isayama H, Kawakubo K, Nakai Y, et al. A novel, fully covered laser-cut nitinol stent with antimigration properties for nonresectable distal malignant biliary obstruction: a multicenter feasibility study. Gut Liver 2013;7(6):725-730

13 Tanisaka Y, Ryozawa S, Kobayashi M, et al. Endoscopic removal of laser-cut covered self-expandable metallic biliary stents: A report of six cases. Mol ClinOncol 2018;8(2):269-273

14 Deprez PH, Moreels TG, Aouattah T, Piessevaux H, PérezCuadrado-Robles E. A new 12-French plastic stent for unresectable distal malignant biliary obstruction. Endoscopy 2020; 52(6):474-482

15 Marui S, Uza N, Yamazaki $\mathrm{H}$, et al. Utility of laser-cut covered self-expandable metal stents for unresectable malignant distal biliary obstruction: a single-center experience. Endoscopy 2020;52(8):664-668

16 Hamada T, Isayama H, Nakai Y, Kogure H, Yamamoto N, Koike $\mathrm{K}$. Tips and troubleshooting for transpapillary metal stenting for distal malignant biliary obstruction. J Hepatobiliary PancreatSci 2014;21(3):E12-E18 